\title{
Type specific persistence of high risk human papillomavirus (HPV) as indicator of high grade cervical squamous intraepithelial lesions in young women: population based prospective follow up study
}

The BMJ wishes to clarify the statement about Dr Meijer's competing interests at the time this paper (BMJ 2002;325:572, doi:10.1136/bmj.325.7364.572) was published. In addition to being an adviser to the company Digene, he had also owned shares in Digene, which he sold in 2001. 